\title{
Implementasi Lean Manufacturing Guna Meminimalisasi Pemborosan Pada Proses Produksi AMDK Jenis Gelas Pada PT.XYZ
}

\author{
Belita Mega Musfita ${ }^{1}$, Nina Aini Mahbubah ${ }^{2 *}$ \\ ${ }^{1,2}$ Program Studi Teknik Industri, Fakultas Teknik, Universitas Muhammadiyah Gresik, \\ Jl. Sumatera 101 GKB Randuagung, Gresik 61121, Indonesia \\ "Koresponden email: mustifapicky@gmail.com
}

Diterima: 21 Desember 2020

Disetujui: 29 Januari 2021

\begin{abstract}
As an industrial manufacture, xyz is an enterprise that produces mineral water should take into account in detail the processes in each production line in order to minimize the cost of activities of valueless activities. The impact of these activities is that they are excessive and inadequate to meet customer orders. The research focused on analysing the activities leading to waste to a glass-type production line based on a lean production approach. A case study based explanation is a research approach. According to the current state map, according to the current state map of wasteacross the value stream, the 'ham-filtering' of speakers and the 'cause of process failure on production lines' remains to be determined . Research shows that the dominant waste of the higher sequence is deliberate, the lead time value is 4320 seconds and the cycle time is 60 seconds. Next, the average consumer product of $7.7 \%$ exceeds the company's maximum standard. Based on value stream flow map, improvement recommendations as follows: minimize waste, disposal of worthless activities, $5 \mathrm{~W} 1 \mathrm{H}$ enhancement on the fish edge diagram and preventative maintenance activities to prevent unavoidable defects along production process activities.
\end{abstract}

Keywords : lean manufacturing, AMDK, waste, current and future state map, FMEA

\begin{abstract}
Abstrak
Sebagai pelaku industri manufaktur, PT. XYZ melakukan perbaikan berkesinambungan pada setiap tahapan produksi guna meminimalisasi kerugian yang diakibatkan oleh adanya aktivitas - aktivitas yang tidak bernilai tambah. Dampak dari adanya aktivitas tersebut yaitu adanya kerugian dikarenakan terjadi pemborosan dan ketidaktepatan memenuhi pesanan pelanggan. Penelitian ini bertujuan menganalisis aktivitas penyebab pemborosan lini produksi jenis gelas melalui pendekatan Lean Manufacturing. Studi kasus berbasis explanatory merupakan pendekatan penelitian ini. Penelitian dimulai dengan menggambarkan current state map guna mengidentifikasi waste yang terjadi sepanjang aliran value stream, dilanjutkan analisis terjadinya aktivitas tanpa nilai tambah di tahapan proses produksi. Hasil penelitian menunjukkan bahwa pemborosan dominan urutan teratas adalah defect, nilai lead time sebesar 4320 detik dan waktu cycle time sebesar 60 detik. Kemudian rata - rata produk reject sebesar 7,7\% melebihi dari standar maksimal perusahaan. Berdasarkan pemetaan yang sudah dilakukan kemudian diberikan rekomendasi perbaikan untuk meminimumkan waste, antara lain eliminiasi aktivitas Non Value Added (NVA), penerapan improvement $5 \mathrm{~W} 1 \mathrm{H}$ pada fishbone diagram dan pengelolaan perawatan mesin berkesinambungan guna mencegah terjadinya defect.
\end{abstract}

Kata Kunci : lean manufacturing, AMDK, pemborosan, value stream map, FMEA

\section{Pendahuluan}

Perkembangan perusahaan manufaktur sekarang ini mengalami persaingan yang sangat ketat. Strategi yang dilakukan tindakan perbaikan terus menerus (continuous improvement), ketepatan dalam mendistribusikan produk pada pelanggan, serta penekanan biaya [1]. Sehingga perusahaan mengalami peningkatan produksi yang dimana jika produksi meningkat maka aktivitas yang tidak memiliki nilai tambah (nonvalue added) juga akan sering terjadi. Aktivitas itulah yang perlu diperhatikan guna menekan terjadinya pemborosan (waste) pada proses produksi. Sehingga output yag dihasilkan dapat memenuhi demand konsumen [2]. Waste (pemborosan) merupakan sebuah kegiatan yang memboroskan sumberdaya yang tidak menambah nilai apapun seperti pengeluaran biaya ataupun waktu tambah dalam kegiatan tersebut [3].

Upaya perbaikan dari aktivitas yang tidak memiliki nilai tambah dari sepanjang value stream yang mengakibatkan hambatan pada proses produksi melalui pendekatan lean manufacturing guna strategi 
perusahaan untuk meningkatkan kualitas dan produktivitas. Bertujuan untuk menekan angka kecacatan, penekanan biaya pemenuhan permintaan konsumen, pengendalian inventory berlebih, serta perbaikan secara kontinu guna meminimasi waste [4].

PT. XYZ adalah suatu perusahaan skala besar dan beroperasi dibidang Air Mineral dalam Kemasan (AMDK). Output produksi diklasifikasikan menjadi 3 yaitu jenis gelas, botol, dan galon. Penjualan produk jenis gelas sangat besar dibandingkan dengan jenis produk yang lainnya, rata-rata peningkatannya sekitar 8\%-9\% pertahun dan diilustrasikan sesuai Gambar 1.

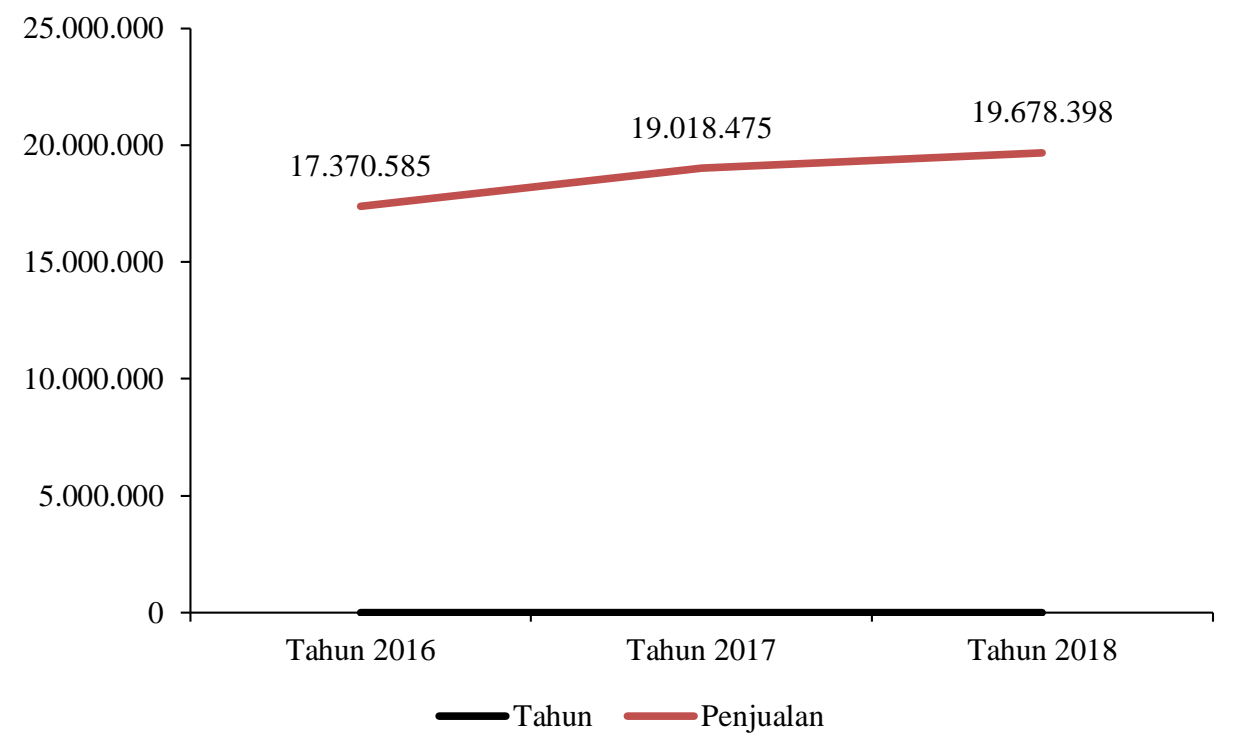

Gambar 1. Grafik penjualan produk AMDK gelas Sumber: Data perusahaan, 2019

Berdasarkan Gambar 1 terlihat bahwa terjadi peningkatan penjualan mengakibatkan aktivitas yang tidak bernilai tambah dan pemborosan juga meningkat. Aktivitas tersebut dapat menyebabkan terjadinya produk defect. Persentase defect yang terjadi dapat dilihat pada Tabel 1 dimana perusahaan perlu melakukan analisis untuk bisa mendapatkan usulan perbaikan permasalahan pada perusahaan.

Tabel 1. Persentase defect pada jenis produk gelas

\begin{tabular}{|c|c|}
\hline Bulan & Defect \\
\hline Januari & $8,10 \%$ \\
\hline Februari & $9,10 \%$ \\
\hline Maret & $9,80 \%$ \\
\hline April & $4,60 \%$ \\
\hline Mei & $9,50 \%$ \\
\hline Juni & $11,20 \%$ \\
\hline Juli & $10,80 \%$ \\
\hline Agustus & $5,30 \%$ \\
\hline September & $8,17 \%$ \\
\hline Oktober & $5.50 \%$ \\
\hline Rata-rata & $7,66 \%$ \\
\hline
\end{tabular}

Berdasarkan Tabel 1, perusahaan perlu melakukan analisis guna mendapatkan usulan perbaikan pada perusahaan. Untuk menganalisis aktivitas tanpa nilaiyang dapat digunakan untuk mengidentifikasi terjadinya waste pada sistem agar perusahaan dapat menghemat sumber daya bahan baku, waktu, dan energi sehingga terjadi peningkatan efisiensi, dibutuhkan suatu perbaikan proses transformasi input menjadi output dan mendapatkan hasil yang optimal. Salah satu pendekatan yang digunakan untuk mengeliminasi waste tersebut adalah lean dengan menggunakan value stream mapping method of manufacturing. Optimal untuk memproduksi barang melalui peniadaan pemborosan atau waste Lean production merupakan suatu proses [5]. Pendekatan lean manufacturing digunakan sebagai suatu sistem manufaktur yang memiliki fokus pada pengendalian kuantitas untuk mengurangi besarnya biaya dengan 
cara menghilangkan waste, memperhatikan aspek kualitas produk, terintegrasi, berkesinambungan, serta dilakukan dengan konsisten sebagai budaya perusahaan [6]. Value Stream Mapping (VSM) adalah alat pencatatan untuk merampingkan proses produksi dari awal sampai akhir membaginya menjadi langkahlangkah peningkatan nilai individu dan non-nilai [7 Penggunaan sebagai alat untuk mengidentifikasi waste dari suatu sistem manufaktur untuk mencari akar permasalahanan pada Value Stream Mapping (VSM) [8].

Penelitian ini bertujuan untuk mengidentifikasi waste yang terjadi pada perusahaan yang mengakibatkan pemborosan, dimulai dengan mengidentifikasi setiap proses dengan bobot waste tertinggi. Kemudian mengidentifikasi faktor-faktor penyebabnya yang terjadi dari setiap proses yang juga mengakibatkan waste terjadi pada proses dengan kategori waste tertinggi. Terakhir melakukan perbaikan pada proses dengan bobot waste merupakan tahap akhir penelitian ini.

\section{Metode Penelitian}

Penelitian ini menggunakan pendekatan studi kasus guna menjelaskan fenomena yaitu adanya ketidakstabilan di aliran informasi dan aliran proses. Implementasi kajian pustaka dalam suatu studi kasus perusahaan air konsumsi merupakan langkah lanjutan guna menganalisis penyebab ketidakstabilan pada lini produksi tersebut. Informasi yang diperlukan dan didapatkan dari data dari aktivitas langsung di proses produksi yaitu defect produk, waktu siklus produk, proses produksi, jam kerja perusahaan, jumlah operator, dan penjualan. Setelah data yang diperlukan didapat dan divalidasi langsung pada bagian produksi dan penjaminan mutu, tahapan selanjutnya adalah melakukan perhitungan waktu standar setiap proses produksi. Value Stream Map merupakan langkah lanjutan sebagai gambaran aliran informasi dan aliran material.Penentuan takt time adalah satuan waktu manakala suatu produk harus diproduksi (tingkat persediaan) agar sesuai dengan tingkat kebutuhan produk itu (tingkat permintaan) [9].

Apabila takt time berada dibawah cycle time maka proses seharusnya dilakukan perbaikan sehingga tersebut bias berjalan lebih lambat. Langkah selanjutnya yaitu rekomendasi perbaikan berbasis $5 \mathrm{~W} 1 \mathrm{H}$ dilakukan dengan upaya perbaikan berdasarkan hasil wawancara, diskusi serta penelitian dan pengamatan langsung dilapangan. Fokus pada usulan perbaikan didasarkan pada analisis terdahulu, yaitu berdasarkan analisis FMEA terkait dengan jenis waste yang telah teridentifikasi dari perhitungan takt time, serta nilai RPN tertinggi yang dihasilkan dari analisis. Penelitian diakhiri dengan tahapan rekomendasi pada perusahaan dan rekomendasi untuk penelitian lanjutan.

\section{Hasil dan Pembahasan}

Konfigurasi current state map dan dilanjutkan dengan análisis value stream, perhitungan cycle tyme $d n$ tatk time, analisis pemborosan dengan nilai RPN tertinggi dan diusulkan suatu perbaikan pada lini produksi dalam suatu future state map. Ini merupakan análisis mendalam dalam upaya perbaikan dan eliminasi aktivitas yang tidak memiliki nilai tambah pada sepanjang aliran proses barang dan aliran informasi.

\section{Konfigurasi Current State Map}

Konfigurasi aliran dalam bentuk value stream map adalah proses produksi yang berlangsung yang digambarkan secara aktual meliputi aliran material dan aliran informasi dalam perusahaan [10]. Diperlukan sebagai langkah awal dalam proses identifikasi waste yang terjadi pada proses produksi AMDK jenis gelas pada pabrik AMDK di PT. XYZ. Gambar 2 Menunjukkan konfigurasi aliran informasi dan konfigurasi aliran proses mulai dari tahapan awal sampai tahapan akhir produksi.

\section{Analisis Current State Map}

Current State Map dijadikan acuan untuk mengidentifikasi pemborosan sepanjang value stream dan dilakukan pengelompokan kegiatan yang termasuk value added (VA), non value added (NVA) dan necessary non-value added (NNVA). Tabel 2 merupakan pengelompokan aktivitas tersebut. 


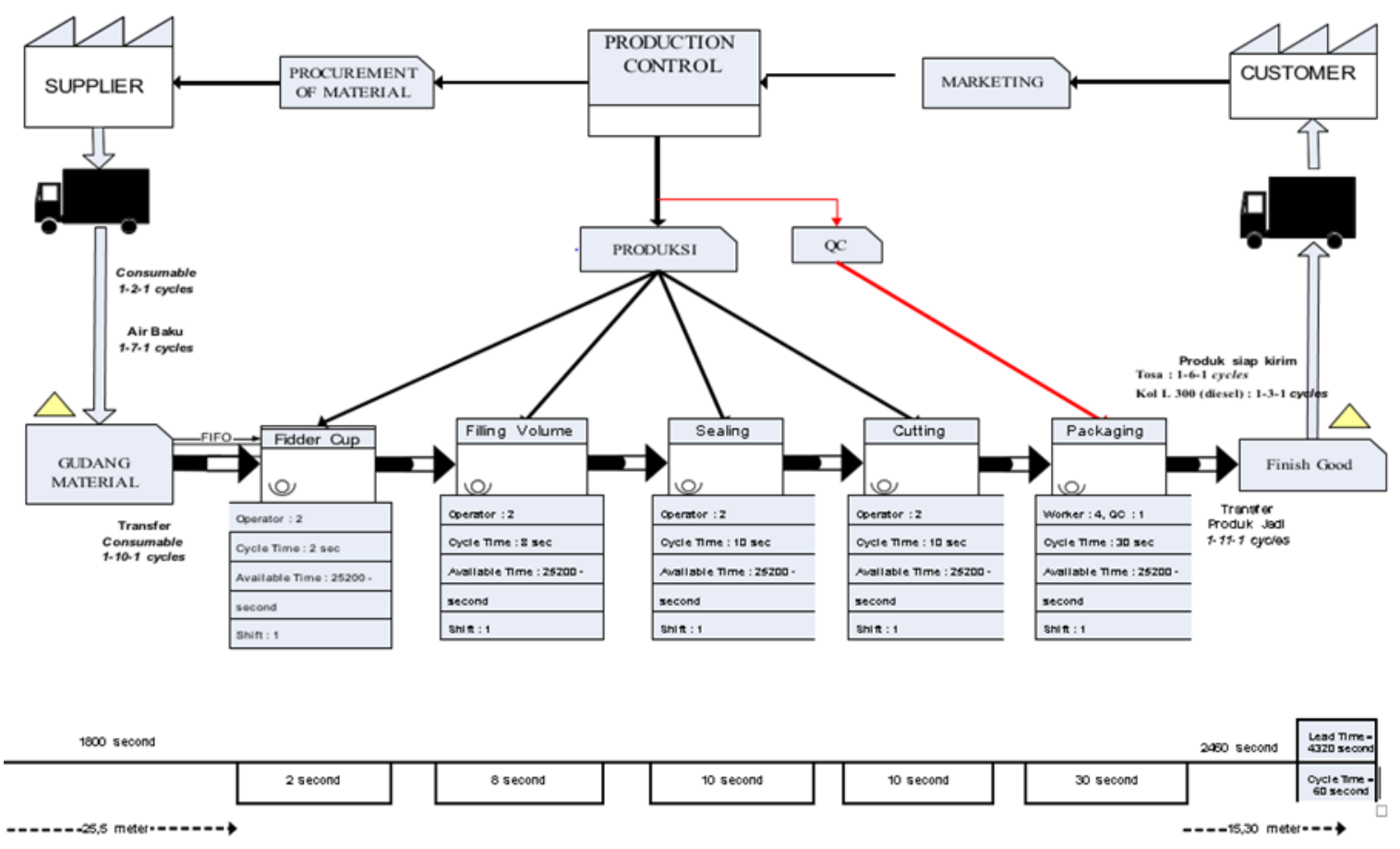

Gambar 2. Current State Map lini produk gelas Sumber: Data penelitian, 2019

Berdasarkan Gambar 2 dapat diketahui aliran proses dan aliran informasi pada proses produksi air mineral kemasan gelas. Berdasarkan perhitungan lead time dan cycle time maka diketahui aktivitas aktivitas dengan nilai dan tanpa nilai tambah atau aktivitas tanpa nilai tambah tetapi merupakan aktivitas penting pada Tabel 2 .

Tabel 2. Pengelompokan VA, NVA, NNVA

\begin{tabular}{|c|c|c|c|}
\hline No & Aktivitas & $\begin{array}{l}\text { Waktu } \\
\text { (second) }\end{array}$ & Kategori \\
\hline 1. & $\begin{array}{l}\text { Inventory awal bahan baku yang datang ditransfer } \\
\text { ketempat penyimpanan material }\end{array}$ & 1800 & NNVA \\
\hline 2. & Pemisahan gelas untuk memulai proses pengemasan & 2,00 & NVA \\
\hline 3. & Pengisian volume air kedalam gelas & 8,00 & VA \\
\hline 4. & $\begin{array}{l}\text { Pengeleman seal terhadap gelas yang sudah terisi air } \\
\text { yang steril }\end{array}$ & 10,0 & VA \\
\hline 5. & Pemotongan seal sesuai bentuk gelas & 10,0 & VA \\
\hline 6. & $\begin{array}{l}\text { Packaging yang dimulai dengan proses pencetakan } \\
\text { tanggal kadarluarsa (codding) dengan melewati proses } \\
\text { quality control diteruskan proses pengemasan jadi ke } \\
\text { dalam karton kardus }\end{array}$ & 30,0 & NNVA \\
\hline 7. & $\begin{array}{l}\text { Produk yang telah jadi di transfer ke gudang produk } \\
\text { akhir dan siap untuk di distribusikan }\end{array}$ & 2450 & NVA \\
\hline
\end{tabular}

Sumber: Data penelitian, 2019

Berdasarkan Tabel 2 diketahui jumlah aktivitas yang memiliki nilai tambah selama 28 detik dan diketahui bahwa aktivitas yang tidak memiliki nilai tambah sepanjang aliran produksi yaitu 2.452 detik.

\section{Analisis Pemborosan (Waste)}

Adapun identifikasi pemborosan yang terdapat di PT XYZ dengan melalui penyebaran kuisoner pada opeator adalah sebagai berikut.

1. Produksi yang berlebih (overproduction)

Aktivitas transformasi input menjadi output jenis gelas memiliki jumlah kerusakan paling besar dibandingkan dengan aktivitas lainnya, yaitu kerusakan rata-rata mencapai $8,18 \%$ per bulan Januari hingga Oktober 2019.

2. Defect

a. Material gelas rusak yang seperti gelas penyok dan lid yang rusak, berasal dari pemasok karena tidak sesuainya kriteria ukuran maupun bahan yang dipesan pihak perusahaan. 
b. Pada proses pengisian volume air :

1) Pengisian volume air kurang dan tidak sesuai standar perusahaan

2) Pemasangan seal yang tidak menempel permukaan gelas secara sempurna

3) Gelas mengalami kelelehan sehingga kerut dan bocor

c. Proses pengemasan karton rusak mengakibatkan terdapat kebocoran yang lolos dalam proses pengemasan.

3. Unnecessary Inventory

Saat menyimpan produk jenis gelas $220 \mathrm{ml}$ yang rusak dalam area penyimpanan.

4. Inappropriate processing

Mengulangi pengecekan terhadap jumlah stok fisik dan informasi consumable 5 Excessive transportation Pemindahan yang tidak sesuai.

5. Excessive transportation

Proses manual masih dilakukan saat proses pemindahan barang seperti pallet dan trolly

6. Waiting (waktu menunggu)

Kerusakan mesin terjadi setiap produksi berlangsung yang membuat waiting time saat perbaikkan

7. Unnecessary motion (Mengulang yang tidak perlu)

Pengemasan berulang baik karena bocor jenis gelas $220 \mathrm{ml}$ dalam satu dus.

Hasil penyebaran kuesioner guna mengidentifikasi waste dapat dilihat pada Tabel 3.

Tabel 3. Rekapitulasi identifikasi waste

\begin{tabular}{|c|c|c|c|c|c|c|c|c|c|c|c|}
\hline \multirow[t]{2}{*}{ Jenis Pemborosan } & \multicolumn{9}{|c|}{ Penilaian Responden } & \multirow[t]{2}{*}{$\begin{array}{l}\text { Skor } \\
\text { rata - rata }\end{array}$} & \multirow[t]{2}{*}{ Ranking } \\
\hline & 1 & 2 & 3 & 4 & 5 & 6 & 7 & 8 & 9 & & \\
\hline Defect & 3 & 4 & 3 & 3 & 3 & 2 & 3 & 3 & 4 & 3.1 & 1 \\
\hline Waiting & 2 & 3 & 3 & 3 & 2 & 3 & 3 & 3 & 3 & 2.7 & 2 \\
\hline $\begin{array}{l}\text { Excessive } \\
\text { Transportation }\end{array}$ & 3 & 3 & 2 & 2 & 3 & 2 & 3 & 2 & 3 & 2.5 & 3 \\
\hline $\begin{array}{l}\text { Inappropriate } \\
\text { Processing }\end{array}$ & 2 & 3 & 3 & 2 & 3 & 2 & 3 & 2 & 2 & 2.4 & 4 \\
\hline $\begin{array}{l}\text { Unnecessary } \\
\text { Inventory }\end{array}$ & 1 & 2 & 2 & 2 & 2 & 3 & 2 & 2 & 3 & 2.1 & 5 \\
\hline Over Production & 2 & 3 & 2 & 2 & 2 & 1 & 2 & 1 & 2 & 1.8 & 6 \\
\hline $\begin{array}{l}\text { Unnecessary } \\
\text { Motion }\end{array}$ & 1 & 2 & 2 & 1 & 2 & 2 & 1 & 1 & 2 & 1.5 & 7 \\
\hline
\end{tabular}

Untuk menekan atau mengurangi jumlah waste yang terjadi didalam produksi dapat dengan mengurutkan persentase terjadinya waste tertinggi produksi dapat dilakukan [11]. Berdasarkan Tabel 3. maka dilakukan perangkingan urutan waste dan ditabulasikan pada Gambar 3. 


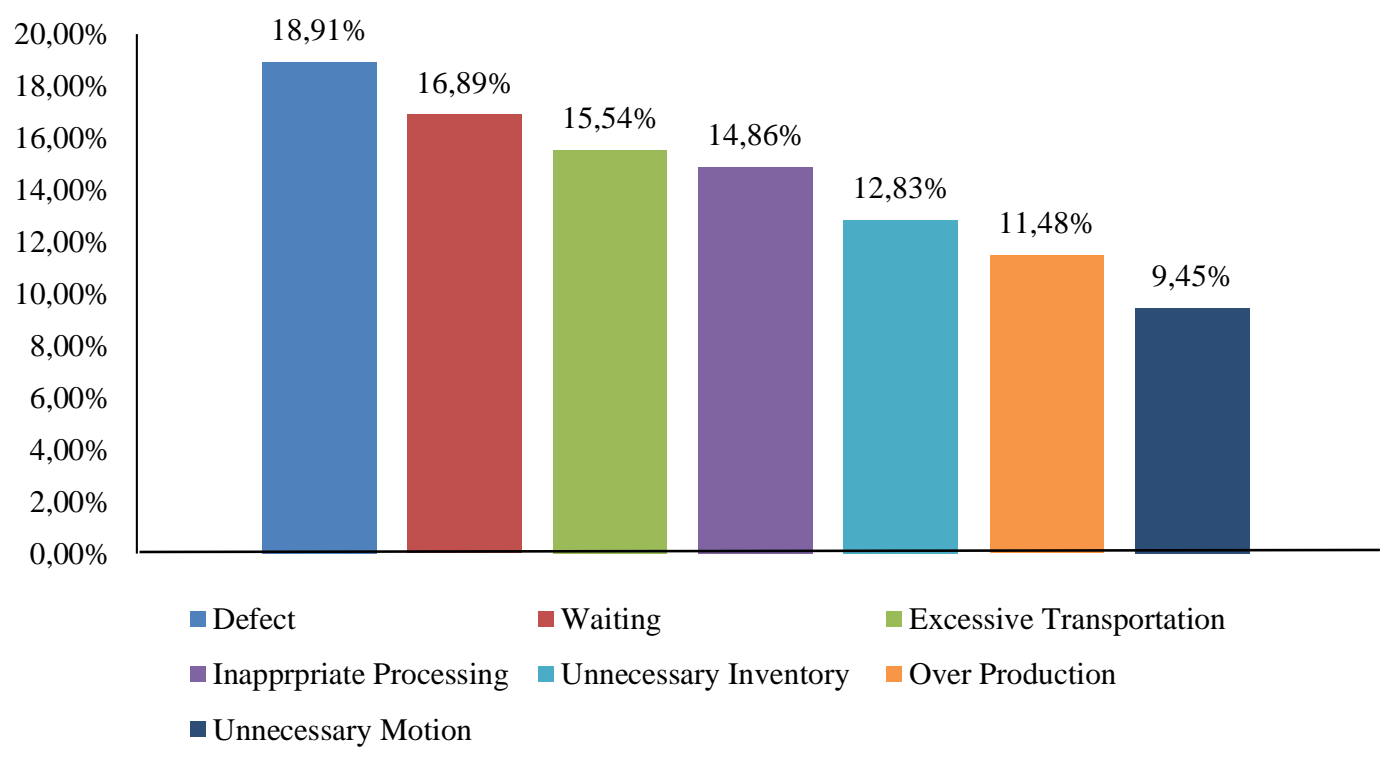

Gambar 3. Grafik rangking waste proses produksi AMDK Gelas Sumber: Data penelitian, 2019

\section{Analisis Penyebab Timbulnya Waste}

Analisis lanjutan guna mengidentifikasi mengapa terjadi kejadian dan aktivitas yang memiliki risiko menyebabkan bottle neck pada aliran barang dan aliran informasi yaitu dengan menggamabrkan suatu konfigurasi dalam diagram sebab akibat. Fishbone diagram merupakan penggambaran secara terperinci dengan memulai dari pertanyaan mengapa terjadi proses dan aktivitas yang tidak memiliki nilai tambah tersebut pada input proses yaitu dari tenaga kerja, bahan baku, metode kerja, lingkungan, alat bantu kerja, dan modal [12]. Fishbone disini dapat dilihat pada Gambar 4.

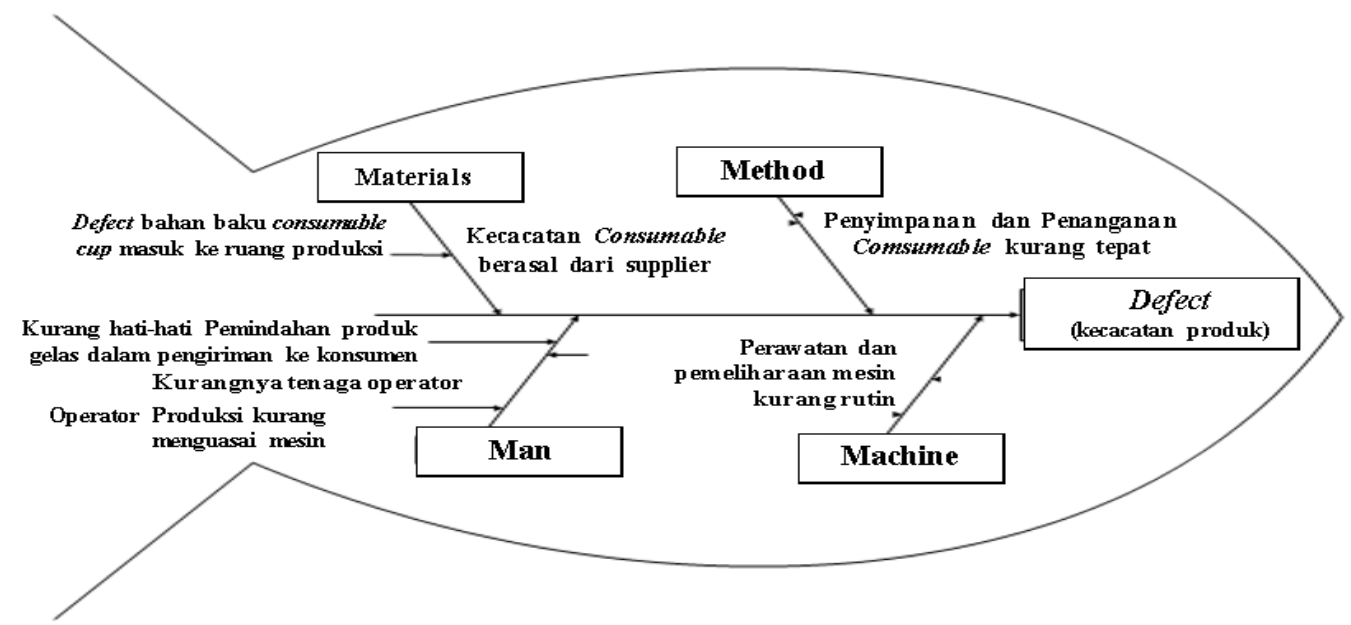

Gambar 4. Diagram fishbone dominan pada jenis waste defect Sumber: Hasil wawancara pada perusahaan, 2019

Berdasarkan analisis yang digambarkan dalam diagram tulang ikan Gambar 4, maka tahapan selanjutnya adalah menganalisis perbaikan menggunakan Why Why analysis disajikan pada Tabel 4.

Tabel 4. Improvement Cause and Effect Waste

\begin{tabular}{|c|c|c|c|}
\hline No. & Penyebab Dominan & How & Improve \\
\hline 1 & $\begin{array}{l}\text { SOP masih kurang } \\
\text { pada rasa } \\
\text { kepedulian dan } \\
\text { pemahaman tenaga } \\
\text { kerja }\end{array}$ & $\begin{array}{l}\text { komunikasi intensif bersamaan } \\
\text { dengan evaluasi antara pihak } \\
\text { atasan dan } \\
\text { pengarahan bawahan, } \\
\text { Penerapan } \text { berkala } r \text { serta } \\
\text { konsisten. }\end{array}$ & $\begin{array}{l}\text { Meningkatkan Total Quality Leadership } \\
\text { untuk Perbaikan. Berkesinambungan } \\
\text { Organisasi sebagai penggerak, Adanya } \\
\text { pendekatan khusus antara atasan dengan } \\
\text { bawahan, evaluasi berkala, tenaga kerja } \\
\text { harus ditekan bekerja sesuai standar, dan } \\
\text { melakukan kontrol secara continue. }\end{array}$ \\
\hline
\end{tabular}


2 Kurangnya operator mesin yang memahami juga penguasaan mesin

3 Penanganan pemindahan produk siap kirim yang kurang tepat

4 Kurang perawatan dan pemeliharaan mesin secara rutin

5 Menunggu

downtime perbaikan mesin

6 Gelas habis pakai rusak yang berasal dari vendor yang lolos ke ruang produksi gelas

7 Gerak transportasi terbatas karena masih minim jalur transportasi khusus

8 Adanya pengerjaan ulang proses packaging atau pengemasan
Pemberian wawasan tentang penggunaan mesin secara tepat, fokus dan terarah.

Pengawasan dari pihak gudang pada petugas pemasaran terkaitpenanganan produk jadi.

Program perawatan yang continue berdasarkan schedule yang ditetapkan serta perlu dan perencanaan preventive dan corrective maintenance.

Dibutuhkan kehati- hatian dan kontrol mesin oleh operator produksi terkait kelancaran proses produksi, gangguan teknis selain

perbaikan mesin secara rutin.

Pembuatan jalur transportasi khususbeserta simbol yang menunjukkan alur lintasan untuk dilewati.

Pembuatanjalur transportasi khusus beserta simbol yang menunjukkan alur lintasan untuk dilewati.

Bekerja dengan hati-hati.
Memberikan training khusus kepada operator agar meningkatkan pemahaman operator dan skill tentang mesin.

Adanya pengawasan secara ketat dari pihak gudang kepada bagian pemasaran distribusi dan melakukan peneguran bila penanganan produk tidak dilakukan dengan baik dan benar.

Melakukan analisis pada setiap hasil record cek list regular tersebut sehingga ada evaluasi perbaikan untuk pencegahan maupun penyelesaian yang sudah terencana berhubungan dengan mesin tersebut.

Secara jelas seperti inspeksi yang harus di check pada mesin dan paham kriterianya, Penerapan pengukuran sendiri oleh operator serta didukung pencegahan kerusakan mesin melalui visual management. Maintenance expected Agar lebih fokus pada dan development dari mesin.

Tindakan Preventif lebih diperjelas melalui Job disk tenaga kerja yang akan melakukan penanganan pengecekkan gelas habis pakai sebelum masuk ke ruang produksi.

Pembuatan layout \& desain workstation yang ergonomi pada jalur transportasi untuk masing-masing transfer barang yang ada

Kesadaran yang ditingkatkan pada semua tenaga kerja untuk bekerja dengan baik dan memperhatikan risiko kecelakaan kerja.

Sumber: Brainstorming pada perusahaan, 2019

\section{Perhitungan Takt Time}

Perhitungan takt time dengan menyesuaikan dengan data yang diperoleh dari PT XYZ, jumlah produk jenis gelas $220 \mathrm{ml}$ yang mempunya permintaan akan rata-rata 33.072 dus tiap bulannya. Dalam 1 bulan terdapat 26 hari kerja sehingga permintaannya 1272 dus /hari.

Pada perusahaan ini terdapat 3 stasiun sehingga kerja 1 stasiun sekitar kerjanya adalah 21 pallet /hari. Untuk jam kerja yang tersedia di perusahaan ini yaitu 7 jam/perhari yaitu 420 menit / hari (time available). Setelah dikurangi dengan waktu istirahat. Perhitungan takt time dilakukan pada setiap proses dimulai dari proses yang paling akhir.

Adapun perhitungan dari takt time untuk proses akhir adalah sebagai berikut:

Proses akhir

Uptime $=95 \% ;$ scrap $=0,01 \%$

Permintaan pelanggan (customer demand) $=21$ pallet/hari : $95 \%(1-0,01 \%)$

$$
=23 \text { pallet/hari }
$$

$$
\begin{aligned}
\text { Takt time } & =\frac{\text { available working time per day }}{\text { customer demand rate per day }} \\
& =\frac{420}{23} \\
& =18,26
\end{aligned}
$$

$$
=18 \mathrm{menit} / \text { pallet }
$$




\section{Implikasi Failure Mode and Effect analysis}

Teknik yang digunakan untuk mengidentifikasi dan eliminasi potensi kegagalan, problem, error yang terjadi pada sistem, desain, proses sebelum sampai pada konsumen maka disebut dengan FMEA (Failure Mode and Effect Analysis) [13]. FMEA dapat diketahui untuk menghasilkan nilai RPN dengan cara mengalikan nilai rating severity, occurance, dan detection. Untuk penentuan kriteria dan rating severity, occurance, dan detection didapatkan dari hasil brainstorming dengan value stream manager di PT XYZ. Yaitu seseorang yang memahami keseluruhan value stream pada proses produksi yang terjadi secara detail dan memiliki peranan penting dalam proses produksi [14].

Adapun kriteria dan rating yang dihasilkan dari severity, occurance, dan detection yaitusebagai berikut. Yang pertama Severity, dimana Severity merupakan tingkat keseriusan waste yang terjadi. Kedua Occurance, yang mana Occurance merupakan rating yang menunjukkan tingkat keseringan terjadinya suatu waste. Dan yang ketiga Detection, yaitu rating yang menunjukkan tingkat kemudahan terdeteksinya suatu waste.

\section{Rekomendasi Perbaikan}

Usulan berdasarkan temuan di lapangan dan hasil perhitungan menggunakan pendekatan Lean manufacturing, difokuskan pada nilai risiko terbesar dari klarifikasi menggunakan pendekatan Failure Mode and Effect Analysis. Adapun usulan perbaikan ditabulasikan pada Tabel 5. Pada Tabel 5 terdapat perhitungan antara identifikasi kegagalan dan jenis kegagalan pada sepanjang alur proses produksi air minum dalam kemasan gelas. Teridentifikasi empat kegagalan yang menyebabkan kondisi tidak adanya nilai tambah dari suatu proses produksi. Kelima jenis kegagalan tersebut adalah bahan baku gelas mengalami kerusakan selama proses produksi, terdapat kebocoran pada bagian atas gelas pada proses sealer, kesalahan pada proses filling yang mengakibatkan volume air pada kemasan gelas ada dibawah dan diatas stándar ukuran yang ditetapkan, dan terdapat pecahan gelas didalam kemasan.

Tabel 5. Perhitungan nilai risk potential number

\begin{tabular}{|c|c|c|c|c|c|c|}
\hline Failure & Saverity & Failure mode & Occurance & $\begin{array}{l}\text { Recomended } \\
\text { Action }\end{array}$ & Detection & $\begin{array}{c}\mathrm{RPN} \\
(\mathrm{SxOxD})\end{array}$ \\
\hline $\begin{array}{l}\text { Bahan } \\
\text { baku } \\
\text { gelas } \\
\text { rusak }\end{array}$ & 5 & $\begin{array}{l}\text { Berasal dari supplier } \\
\text { karena tidak } \\
\text { sesuainya kriteria } \\
\text { ukuran maupun } \\
\text { pesanan bahan pihak } \\
\text { perusahaan seperti } \\
\text { gelas pecah dan lid } \\
\text { yang rusak karena } \\
\text { mengkerut }\end{array}$ & 3 & \begin{tabular}{l}
\multicolumn{2}{l}{ Lebih menyeleksi } \\
dalam pemilihan \\
suplier bahan \\
baku dengan \\
banyak \\
pertimbangan \\
yang perlu \\
dilakukan \\
sehingga \\
kerusakan bahan \\
baku dari suplier \\
bisa maksimal
\end{tabular} & 4 & 60 \\
\hline \multirow[t]{2}{*}{$\begin{array}{l}\text { Bocor } \\
\text { atas }\end{array}$} & 6 & $\begin{array}{l}\text { Kurangnya } \\
\text { pengawasan operator } \\
\text { pada mesin }\end{array}$ & 5 & $\begin{array}{l}\text { Melakukan } \\
\text { penambahan } \\
\text { pemeliharaan dan } \\
\text { pengaturan mesin }\end{array}$ & 3 & 90 \\
\hline & & $\begin{array}{lr}\text { Ada settingan suhu } \\
\text { mesin pressing yang } \\
\text { kurang } & \text { persisi } \\
\text { sehingga mengalami } \\
\text { kebocoran } & \text { pada } \\
\text { mulut gelas } & \end{array}$ & 4 & $\begin{array}{lr}\text { Memperbaiki } \\
\text { sistem } & \text { settingan } \\
\text { pada } & \text { mesin } \\
\text { pressing } & \end{array}$ & 2 & 48 \\
\hline $\begin{array}{l}\text { Volume } \\
\text { dibawah } \\
\text { standart }\end{array}$ & 4 & $\begin{array}{lr}\text { Settingan } & \text { mesin } \\
\text { filling } & \text { terkadang } \\
\text { mengalami } & \\
\text { pengisihan } & \text { yang } \\
\text { kurang } & \text { dibawah } \\
\text { standart perusahaan }\end{array}$ & 3 & $\begin{array}{l}\text { Melakukan rutin } \\
\text { pengecekan } \\
\text { mesin filling }\end{array}$ & 3 & 36 \\
\hline $\begin{array}{l}\text { Pecah } \\
\text { gelas } \\
\text { badan }\end{array}$ & 4 & \begin{tabular}{lr}
\multicolumn{2}{l}{ Adanya tekanan yang } \\
keras saat & pressing \\
ataupun & cutting \\
terhadap & material, \\
dorongan, & serta
\end{tabular} & 4 & $\begin{array}{l}\text { Memperbaiki } \\
\text { settingan pada } \\
\text { mesin press atau } \\
\text { cutting } \\
\text { memperbaiki tata }\end{array}$ & 2 & 32 \\
\hline
\end{tabular}




adanya materal yang
jatuh saat proses
pemindahan ke
proses selanjutnya
Proses repack
ataupun repair yang
kurang maksimal

letak proses
pemindahan
material

$$
\begin{aligned}
& \text { Memperbaiki } \\
& \text { kinerja karyawan } \\
& \text { dengan diberikan } \\
& \text { training, dll } \\
& \text { sehingga proses } \\
& \text { lebih maksimal }
\end{aligned}
$$

Sumber: Data hasil brainstorming, 2019

Berdasarkan hasil perhitungan antara tingkat keparahan kerusakan, frekuensi kejadian, dan kemungkinan deteksi kerusakan tersebut, maka didapatkan nilai perhitungan Risk Potential Number tertinggi yaitu 90 pada kerusakan gelas bocor di bagian atas, RN sebesar 60 terjadi pada defect material yang mengalami kerusakan dan 48 pada mode kegagalan kesalahan setting suhu mesin yang mengakibatkan material meleleh dan menyebabkan kebocoran proses sealing. Kesalahan setting mesin yang disebabkan operator mengakibatkan volume isian tidak memenuhi standar menghasilkan nilai RPN 36. Tekanan berlebihan pada proses pressing menyebabkan gelas pecah mendapatkan nilai RPN 32 dan nilai 24 untuk proses repack dan repair kurang sempurna. Rekomendasi perbaikan difokuskan pada nilai RPN tertinggi dan dilaksanakan pada jangka pendek agar fokus perusahaan dalam memenuhi permintaan konsumen sesuai jadwal dapat dilaksanakan tepat waktu.

\section{Future State Map}

Future state map merupakan bagian dari perbaikan berkelanjutan (continuous improvement), sehingga pada kondisi perbaikan yang diusulkan tercapai [15]. Berdasarkan rekomendasi why why analysis dan analisis Risk Potential Number, maka konfigurasi Future State Map sebagai implementasi dari rekomendasi tersebut dapat dilihat pada Gambar 5.
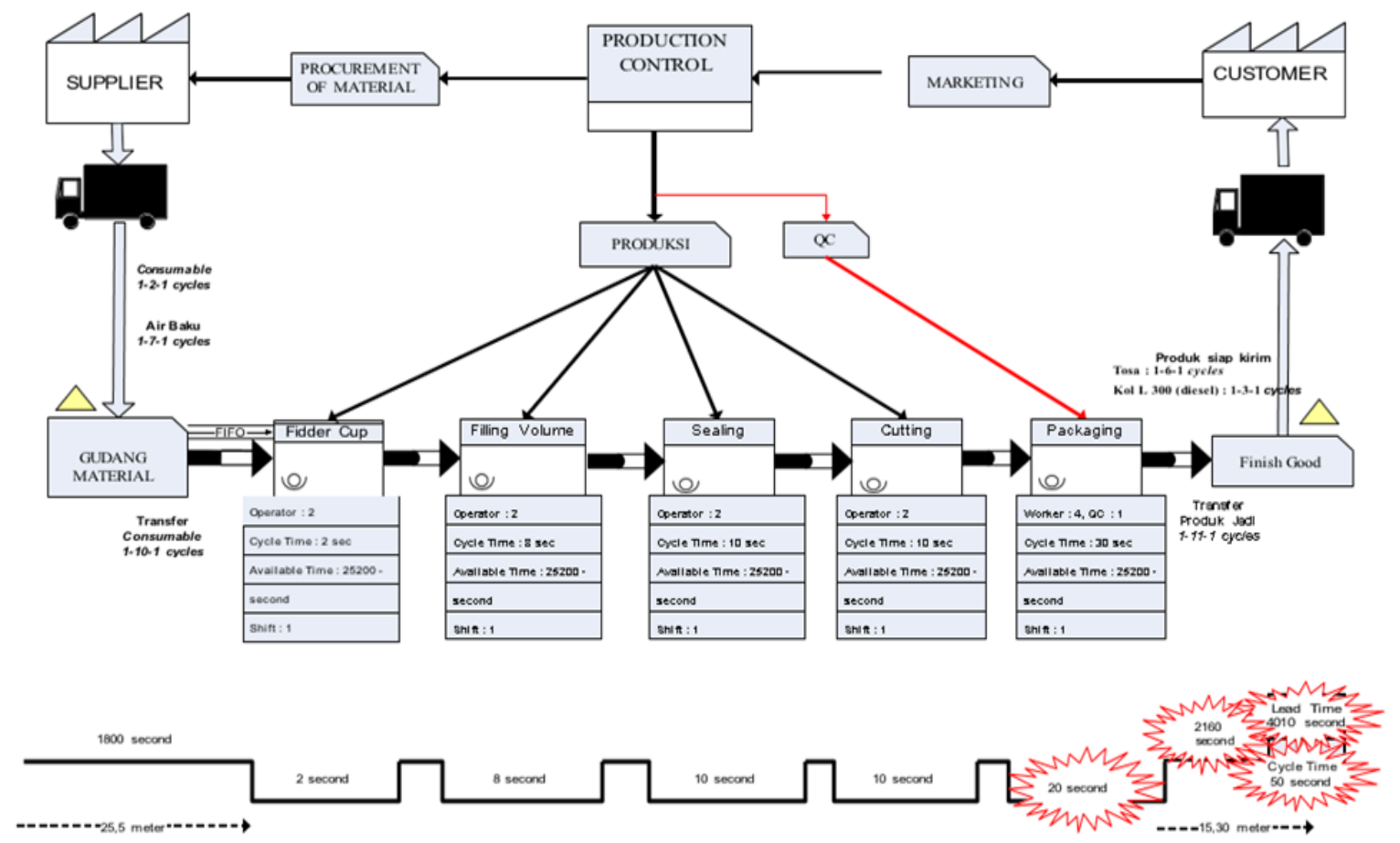

Gambar 5. Future State Value Stream Mapping

Sumber: Pengolahan data penelitian, 2019

Siklus aliran supply consumable adalah 1-2-1 cycles yang artinya dalam sehari rata-rata ada dua kali kedatangan yang disimpan pada gudang penyimpanan raw material, dengan kapasitas 55.000 pcs. Sedangkan supply air baku 1-7-1 cycles yang artinya dalam sehari bisa mencapai tujuh kali pendatangan air baku dengan kapasitas 5.000 hingga 8.000 liter, kemudian disimpan dengan rata-rata waktu kedatangan tiap empat jam sekali. 
Sebelum produksi dimulai, dilakukan penyiapan mesin dan transfer consumable ke ruang produksi AMDK jenis gelas dalam waktu sekitar 30 menit dengan 1-10-1 cycles yang artinya dalam sehari bisa sampai sepuluh kali transfer consumable bahkan lebih. Setelah persiapan pemanasan dan material selanjutnya dilakukan proses produksi pada lini produksi AMDK jenis gelas dan total waktu menunggu packaging dalam satu pallet dan transfer ke gudang penyimpanan mencapai 41 menit.

Transfer produk jadi menggunakan alat pallet dan trolly, kapasitas pallet sekitar 60 dus yang ditransfer ke gudang penyimpanan dengan 1-11-1 cycles yang artinya dalam sehari jika aliran proses lancar bisa mencapai 11 kali transfer produk jadi. Proses akhir siap dikirim pada konsumen dari pukul 08.00 wib sampai dengan pukul 16.00 wib, pengiriman menggunakan Tosa 1-6-1 cycles yang artinya dalam sehari bisa mencapai enam kali pengiriman dan penggunaan kol L 300 (diesel) 1-3-1 yang artinya dalam sehari rata-rata bisa sampai tiga kali pengiriman. Melalui gambaran current state value stream map diketahui hasil waktu lead time yang diperoleh yaitu 4320 detik dan total cycle time yang diperoleh 60 detik.

Dari hasil analisis diatas, maka rencana perbaikan dalam pembuatan future state value stream mapping sebagai berikut:

1. Kapasitas Produksi: Waktu untuk menghasilkan produk jenis gelas sudah sesuai standar kapasitas output berdasarkan mesin maka dapat dikatakan masih normal, Antisipasi yang perlu dilakukan hanya perlu perbaikan untuk menjaga pemenuhan permintaan konsumen dapat dipenuhi tanpa seringnya overtime atau kerja lembur dari faktor gangguan kelancaran mesin produksi yang sewaktu-waktu terjadi.

2. Efektifitas waktu: Perlunya dilakukan minimasi pada waktu penanganan packaging oleh pekerja, agar selesai tepat waktu disamping kendala yang terjadi pada proses penanganan tenaga kerja dan adanya gangguan pada mesin produksi jenis gelas yang tidak dapat diprediksi secara pasti. Hasil pengukuran peneliti selama terjun dilapangan, waktu yang dibutuhkan untuk proses packaging satu pallet produk jenis gelas rata-rata sekitar 2100 detik dan waktu packaging satu dus sekitar 20 detik. Sehingga waktu yang dihasilkan untuk packaging produk dalam satu pallet mendapatkan minimalisir waktu sebesar 300 detik dan waktu packaging satu dus mendapatkan minimalisir 10 detik, maka hasil upaya perbaikan untuk minimalkan waste dari segi efektifitas waktu dalam siklus produksi pada lini jenis gelas yang menunjukkan waktu lead time sebesari 4020 detik dan untuk cycle time 50 detik. Hasil usulan perbaikan tersebut dapat dilihat pada Gambar 5. future state value stream mapping.

\section{Kesimpulan}

Hasil analisis dari aktivitas - aktivitas yang tidak memiliki nilai tambah sepanjang konfigurasi aliran produksi dan aliran informasi pada produksi persahaan PT. XYZ sebagai upaya minimasi waste pada proses adalah melakukan upaya tindakan sebagai usulan perbaikan pada aktivitas penyebab waste secara keseluruhan yang mendominasi, menggunakan 5what's dan 1 How's untuk usulan perbaikan. Peningkatan complete quality management, upaya pendekatan khusus atasan dengan bawahan, bekerja sesuai standar, continuation dilakukan secara pengontrolan, dan evaluasi berkala merupakan masukan bagi perusahaan guna penigkatan production produksi berbasis eliminasi pemborosan. Pelaksanaan khusus kepada training operator dapat dilakukan secara berkalaa operator agar dalam pelaksanaannya operator di lapangan mampu mengimplementasikan hasil temuan dari kesalahan yang dilakukan pada periode produksi sebelumnya.

Pengetatan pengawasan kepada petugas pemasaran dari pihak gudang merupakan rekomendasi selanjutnya. Penggunaan teknologi dalam pengawasan diperlukan guna menjamin keakuratan dan evaluasi pada proses tersebut. Hal tersebut dapat diimplementasikan disertai dengan analisis hasil record cek list regular secara berkala dan tindakan evaluasi. Perusahaan menetapkan penerapan autonomous maintenance atau pengukuran sendiri oleh operator serta didukung visual management secara jelas menjadi harapan untukkelanjutan kedepannya. Kejelasan Job disk yang lebih ditingkatkan terkait penanganan pengecekkan gelas habis pakai sebelum masuk ruang produksi. Rekomendasi terakhir untuk mengeliminasi aktivitas yang tidak menyebabkan nilai tambah yaitu perusahaan diharapkan desain layout dan desain workstation yang lebih ergonomi pada jalur perpindahan barang dan aktifitas produksi. Juga kepada semua tenaga kerja untuk lebih meningkatkan kesadaran dalam bekerja dengan baik dan maksimal. 


\section{Referensi}

[1] S. Sinulingga, Perencanaan dan Pengendalian Produksi Edisi Pertama, Yogyakarta: Graha Ilmu, 2013.

[2] D. Pujotomo, D. N. Rusanti, "Usulan Perbaikan Untuk Meningkatkan Produktivitas Filling Plant Dengan Pendekatan Lean Manufacturing Pada PT. Smart Tbk Surabaya," J. Teknik Industri, 2015.

[3] S. Andiyanto, A. Sutrisno, C. Punushingon, "Penerapan Metode FMEA (Failure Mode and Effect Analysis) Untuk Kuantifikasi Dan Pencegahan Resiko Akibat Terjadinya Lean Waste," J. Online Poros Teknik Mesin, vol. 6, 2017.

[4] S. Arslankaya, H. Atay, "11 th International Strategic Management Conference 2015 Maintenance management and lean manufacturing practices in a firm which produces dairy products," Procedia - Social and Behavioral Sciences, vol. 207, pp. 214-224, 2015.

[5] L. Wilson, How to Implement Lean Manufacturing, USA: McGraw-Hill, 2010.

[6] F. Abdulmalek, J. Rajgopal, "Analizing the Benefits of Lean Manufacturing and Value Stream Mapping Via Simulation,” Int. J. Production Economics, 107 (1), pp. 223-236, 2020.

[7] W. Li, S. Thiede, S. Kara, C. Herrmann, "A Generic Sankey Tool for Evaluating Energy Value Stream in Manufacturing Systems," The 24th CIRP Conference on Life Cycle Engineering, pp. 475-480, 2017.

[8] T. Satria, E. Yuliawati, "Perancangan Lean Manufacturing dengan Menggunakan Waste Assessment Model (WAM) dan VALSAT untuk Meminimumkan Waste," J. Rekayasa Sistem Industri, vol. 07, 2018.

[9] X. Brioso, D. Murguia, A. Urbina, "Waktu pengambilan barang adalah satuan waktu manakala suatu produk harus diproduksi (tingkat persediaan) agar sesuai dengan tingkat kebutuhan produk itu (tingkat permintaan)," Creative Construction Conference, 2017.

[10] Andri, D. Sembiring, "Penerapan Lean Manufacturing Dengan Metode VSM (Value Sream Mapping) Untuk Mengurangi Waste Pada Proses Produksi PT.XYZ," J. Rekayasa dan Manajemen Sistem Industri, vol. 11, pp. 303-309, 2018.

[11] A. Raviza, R. Rosihin, "Penerapan Lean Manufacturing Untuk Mengurangi Waste Pada Produksi Absorbent," J. INTECH, vol. 4, 2018.

[12] I. N. Octaviany, A. A. Yanuar, M. Rendra, "Implementation of Lean Manufacturing to Minimize Waiting Waste on Hanger Sample Production Process at CV. ABC Offset," J. Rekayasa Sistem \& Industri, 2017.

[13] A. Rachman, H. Adianto, G. P. Liansari, "Perbaikan Kualitas Produk Ubin Semen Menggunakan Metode Failure Mode And Effect Analysis dan Failure Tree Analysis di Institusi Keramik," J. Online Institut Teknologi Nasional, Vol. 4, 2016.

[14] B. Musyahidah, M. Choiri, I. Hamdala, "Implementasi Metode Value Stream Mapping Sebagai Upaya Meminimalkan Waste (Studi Kasus: Sub bagian Assembly di PT Selatan Jadi Jaya, Sidoarjo)," J. Rekayasa dan Manajemen Sistem Industri, vol. 3, 2015.

[15] O.K. A. R. Damanik, V. M. Afma, B. A. H. Siboro, "Analisa Pendekatan Lean Manufacturing Dengan Metode VSM (Value Stream Mapping) Untuk Mengurangi Pemborosan Waktu (Studi Kasus UD. Almaida)," J. Unrika,vol. 5, 2017 